\title{
CISTO EPIDÉRMICO PRÉ-SACRAL NO ADULTO
}

\author{
PRESACRAL EPIDERMAL CYST IN ADULT
}

\begin{abstract}
Marcelo Betim Paes Leme; TCBC-RJ ${ }^{1}$
Evandro de Morais e Silva; TCBC-RJ ${ }^{2}$
\end{abstract}

\section{INTRODUÇÃO}

Os tumores do espaço pré-sacral (ou retrorretal) no adulto são infrequientes e poucos cirurgiões têm acumulado experiência significativa com eles. $\mathrm{O}$ espaço pré-sacral é delimitado anteriormente pelo reto e posteriormente pelo sacro e cóccix. O músculo elevador do ânus e os músculos coccígeos formam o limite inferior. O limite superior é a reflexão pélvica do peritônio ${ }^{1}$.

Em que pese a grande variedade de tumores que ocorrem neste espaço ${ }^{2}$, a maior parte é de origem congênita, entre estes os cistos de desenvolvimento, que incluem os epidérmicos, são os mais comuns ${ }^{3}$. O diagnóstico definitivo só é firmado pelo exame histológico, entretanto a biópsia pré-operatória das lesões císticas pode ser perigosa e na maioria das vezes está contra-indicada ${ }^{4}$.

Assim, a incerteza diagnóstica implica a indicação de operação e ressecção completa do cisto para estabelecimento do diagnóstico histológico definitivo, já que alguns são malignos ${ }^{5}$.

\section{RELATO DO CASO}

Paciente feminina, branca, 29 anos foi atendida no ambulatório de coloproctologia do Hospital São João Batista/UniFoa, com queixa de tumoração em região perianal que surgiu há um ano e que há três meses começou incomodá-la, com dificuldade para sentar em decorrência do aumento da lesão. A paciente não referia qualquer outro sintoma.

Ao exame físico verificava-se abaulamento em região perianal na projeção do quadrante posterior direito. Ao toque retal notava-se tumor de consistência fibroelástica que deslocava anteriormente a parede posterior do reto; o limite proximal localizava-se a cerca de $6 \mathrm{~cm}$ da borda anal.

A retossigmoidoscopia não revelou comprometimento da mucosa retal. A TC de região pélvica demonstrou tumoração cística de conteúdo denso em região pré-sacrococcígea de $6 \times 3 \mathrm{~cm}$ (Figura 1 ).

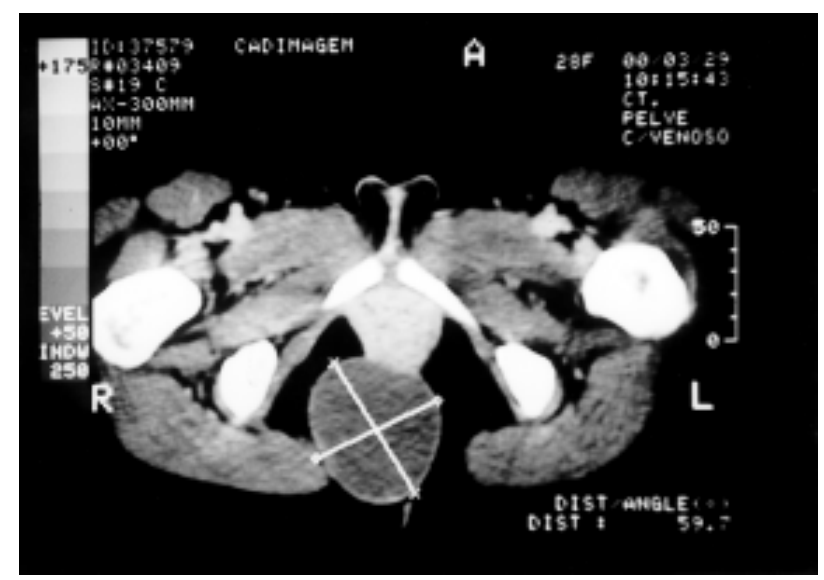

Figura 1 - Tomografia mostrando lesão cística em região présacro-coccígea.

A paciente foi submetida à operação no dia 02/06/2000 através de acesso posterior e incisão para-sacral direita. Após a secção do ligamento anococcígeo foi identificada tumoração cística bem delimitada (Figura 2). Realizada ressecção do cisto, o leito operatório foi drenado com dreno de sucção. A paciente evoluiu sem complicações ou seqüelas, recebendo alta no terceiro dia de pós-operatório.

$\mathrm{O}$ estudo histopatológico revelou formação cística de $7,0 \times 5,5 \mathrm{~cm}$ cujo corte demonstrou parede delgada e conteúdo grumoso e acinzentado. A microscopia demonstrou tratar-se de cisto epidérmico, cujo revestimento caracteriza-se pela presença de epitélio escamoso estratificado sem anexos cutâneos.

\section{DISCUSSÃO}

Mais da metade dos tumores pré-sacros é congênita e dois terços desses são cistos de desenvolvimento ${ }^{3}$. Estes cistos são classificados em epidérmicos, que possuem epi-

1. Professor Assistente de Clínica Cirúrgica do Centro Universitário de Volta Redonda - UniFOA. Mestre em Gastroenterologia Cirúrgica pela UNIFESP — Escola Paulista de Medicina. Cirurgião do Hospital São João Batista/UniFOA

2. Professor Assistente de Anatomia Humana do Centro Universitário de Volta Redonda - UniFOA. Cirurgião do Hospital São João Batista/UniFOA.

Recebido em 12/12/2000

Aceito para publicação em 14/08/2001

Trabalho realizado no Serviço de Cirurgia do Hospital São João Batista/UniFOA — Volta Redonda 


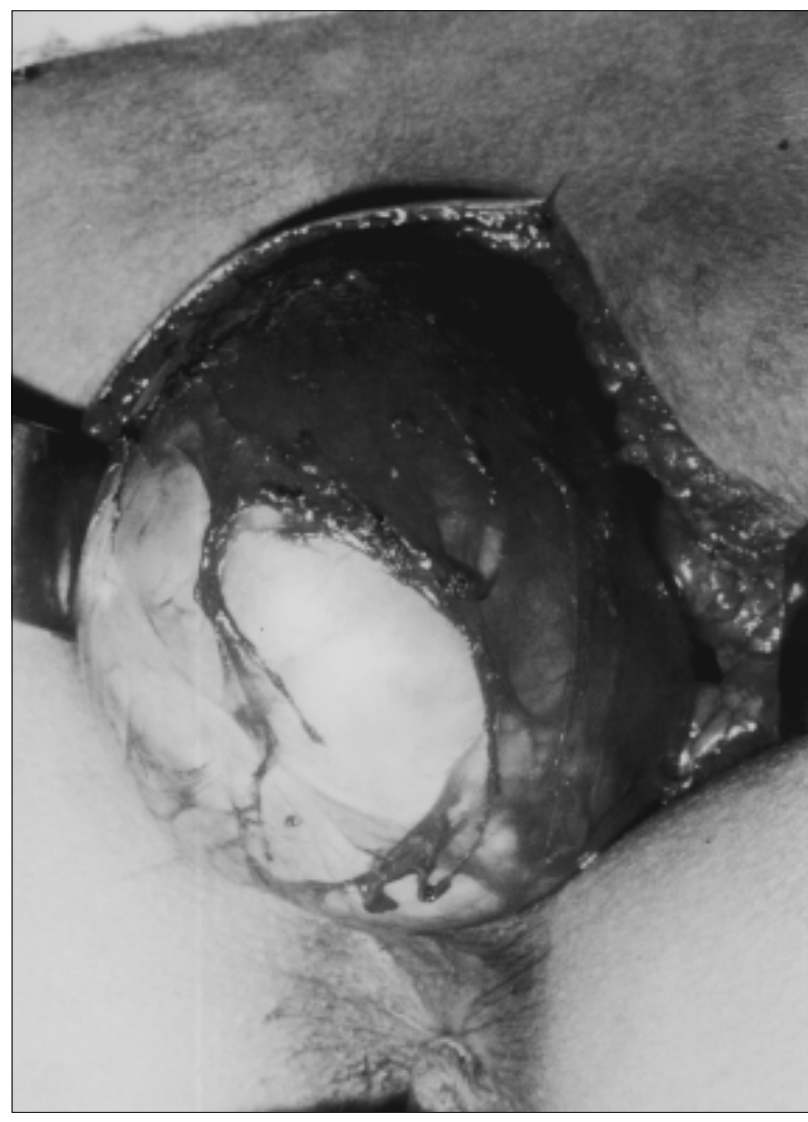

Figura 2 - Aspecto transoperatório da ressecção do cisto por via posterior.

télio escamoso estratificado com queratina, porém sem apêndices cutâneos; cistos dermóides, que apresentam epitélio escamoso e apêndices cutâneos; cistos mucossecretores, revestidos por epitélio colunar de origem endodérmica e os teratomas que contêm pelo menos dois dos três folhetos embrionários e podem apresentar pêlos, ossos e dentes ${ }^{4}$. A grande maioria desses cistos é benigna, entretanto a degeneração maligna é possível e ocorre em cerca de $10 \%$ dos casos verificados em pacientes adultos ${ }^{3}$.

Os cistos congênitos epidérmicos são mais comuns nas mulheres ${ }^{2}$. Sua freqüência tem sido relatada como variando entre $0,9 \%$ e $12,5 \%$ (média de $6,2 \%$ ) de todos os tumores do espaço pré-sacral (Tabela 1$)^{5}$.

A maioria dos cistos congênitos é assintomática. Os sintomas, quando existem, dependem do tamanho e da posição do cisto ${ }^{2}$. Muitos pacientes descobrem a tumora-
Tabela 1

Freqüência do cisto epidérmico em tumores pré-sacrais ${ }^{5}$

\begin{tabular}{lcc}
\hline Autor & Freqüência & Período \\
\hline Uhlig et al. & $1 / 63$ & $1945-1975$ \\
Jao et al. & $15 / 120$ & $1960-1979$ \\
MacCarty et al. & $6 / 52$ & $1949-1961$ \\
Hurdling et al. & $1 / 19$ & 1922 \\
Jackman et al. & $1 / 114$ & $1937-1948$ \\
Spencer et al. & $1 / 38$ & $1956-1960$ \\
\hline \multicolumn{3}{c}{ Total } \\
\hline
\end{tabular}

ção pelo incômodo ao sentar ou após uma queda ${ }^{1}$. Quando existe infecção ocorre dor perineal, febre e descarga purulenta. Todos pacientes que apresentam fracassos múltiplos no tratamento de uma supuração perianal devem ser pesquisados para possibilidade de cisto pré-sacral ${ }^{1}$.

O exame retal constitui a chave diagnóstica: $97 \%$ dos tumores são palpáveis ao toque retal ${ }^{4}$. A retossigmoidoscopia pode revelar uma compressão extrínseca quando existe uma grande tumoração ${ }^{4}$. Usualmente a mucosa tem aspecto normal ${ }^{3}$

Os exames de imagem, especialmente a TC, determinam detalhadamente o tamanho da tumoração, sua relação com o sacro e outras estruturas como bexiga, ureteres e vasos ilíacos. A tomografia também pode diferenciar os tumores sólidos dos císticos.

Uma vez estabelecido o diagnóstico de cisto pré-sacral o tratamento deve ser a ressecção completa, evitando-se a sua rotura. Mesmo quando assintomáticos esses cistos devem ser ressecados por duas razões: degeneração maligna e infecção recorrente. Essa última tem sido relatada como sendo um fator que aumenta as chances de incontinência e recidiva em decorrência de dificuldades técnicas por ocasião do tratamento cirúrgico definitivo ${ }^{4}$.

O tratamento operatório pode ser realizado por abordagem posterior, abdominal ou combinada. A escolha da via de acesso é feita considerando-se o tamanho, a localização e as características do cisto. A abordagem posterior, utilizada neste caso, é a ideal para cistos distais ${ }^{3}$; a ressecção do cóccix, indicada por alguns autores, tem sido considerada desnecessária por outros. A via abdominal está indicada para grandes cistos especialmente os de posição mais alta ${ }^{5}$.

\begin{abstract}
Presacral tumors are relatively uncommon. We report a case of presacral epidermal cyst in a 29-years-old female, which was completely extirpated through a posterior approach, whitout removal of the coccyx. Histological examination showed a cyst lined by keratinized stratified squamous epithelium.
\end{abstract}

Key Words: Epidermal cyst; Presacral tumor. 


\section{REFERÊNCIAS}

1. Uhlig BE, Johnson RL Presacral tumors and cysts in adults. Dis Colon Rectum, 1975, 18:581-596.

2. Tokunaga Y, Mukaihara S, Tanaka M et al. Presacral epidermal cyst found in an adult male with a high CEA content: report of an unusual case. Jpn J Surg, 1994, 24:556-560.

3. Wexner SD, Jagelman DG. Pilonidal sinus, pre-sacral cysts and tumors and pelvic pain. In: Zuidema GD, Condon RE. Surgery of the alimentary tract $\left(3^{\text {rd }}\right.$ ed $)$. Philadelphia. WB Saunders Co., 1991; pp.390-405.

4. Jao SW, Beart RW, Spencer RJ et al. Retrorectal Tumors. Mayo clinic experience, 1960-1979. Dis Colon Rectum, 1985, 28:644-652.
5. Midorikawa Y, Kubota K, Koyama $\mathrm{H}$ et al. Presacral epidermal cyst: a report of an adult case. Hepato-Gastroenterology, 1996, 46:1399-1402.

Endereço para correspondência:

Dr. Marcelo Betim Paes Leme

Rua Moacir de Paula Lobo, 19

27283-350 - Volta Redonda-RJ

E-mail: marcelo.leme@uol.com.br 